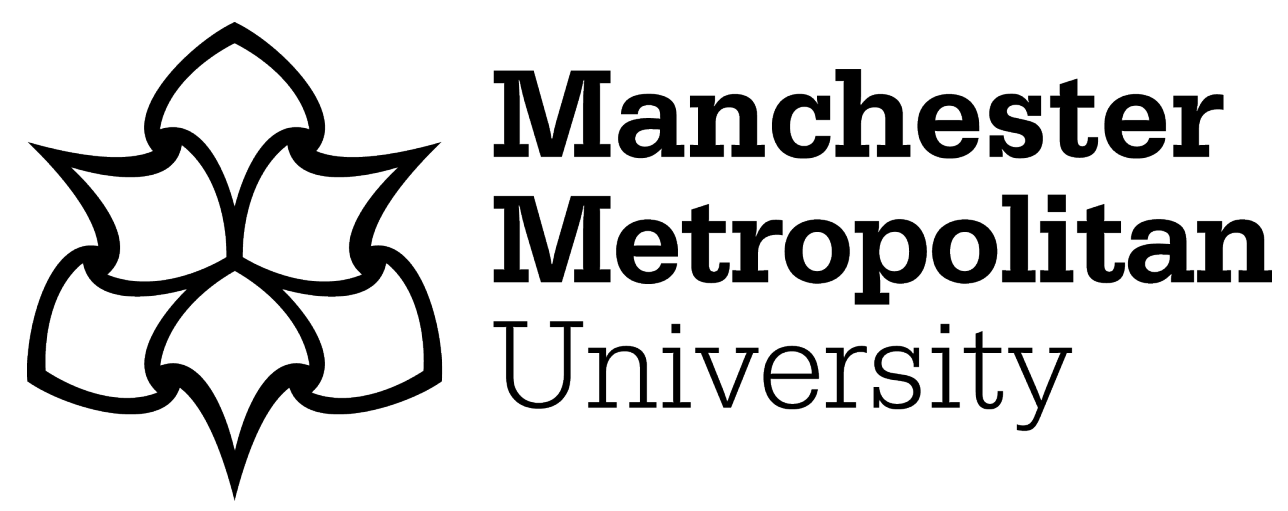

Hajimirzaee, Saeed, Chansai, Sarayute, Hardacre, Christopher, Banks, Craig E and Doyle, Aidan M ORCID logoORCID: https://orcid.org/0000-00025800-0412 (2019) Effects of surfactant on morphology, chemical properties and catalytic activity of hydroxyapatite. Journal of Solid State Chemistry, 276. pp. 345-351. ISSN 0022-4596

Downloaded from: https://e-space.mmu.ac.uk/623035/

Version: Accepted Version

Publisher: Elsevier BV

DOI: https://doi.org/10.1016/j.jssc.2019.05.031

Usage rights: Creative Commons: Attribution-Noncommercial-No Derivative Works 4.0

Please cite the published version 


\title{
Effects of surfactant on morphology, chemical properties and catalytic activity of hydroxyapatite
}

\author{
Saeed Hajimirzaee ${ }^{1}$, Sarayute Chansai ${ }^{2}$, Christopher Hardacre ${ }^{2}$, Craig E. Banks ${ }^{1}$, Aidan M. Doyle ${ }^{1 *}$ \\ ${ }^{1}$ Faculty of Science and Engineering, Manchester Metropolitan University, Chester Street, Manchester M1 5GD, United \\ Kingdom; \\ ${ }^{2}$ School of Chemical Engineering and Analytical Science, University of Manchester, Sackville Street, Manchester, M1 3BB, \\ United Kingdom \\ * corresponding author a.m.doyle@mmu.ac.uk
}

\begin{abstract}
Hydroxyapatite (HAP) was synthesised in the presence of surfactants and tested as a catalyst in $\mathrm{CO}$ oxidation. XRD confirmed that the characteristic HAP crystal phase was practically unaffected by the addition of surfactant. The surfactant altered both the $\mathrm{Ca} / \mathrm{P}$ ratio and particle size of HAP. Catalyst tests showed that the activity of HAP increased for preparations using TWEEN, PEG and PVA. The temperature for $50 \%$ conversion, $\mathrm{T}_{50}$, values decreased from $340{ }^{\circ} \mathrm{C}$ for unmodified $\mathrm{HAP}$, to $320^{\circ} \mathrm{C}$ for TWEEN and to $315^{\circ} \mathrm{C}$ for both PEG and PVA. This enhanced activity is rationalised by the higher BET surface areas and acid site densities in the surfactant-modified preparations: these increased from $52 \mathrm{~m}^{2}$ $\mathrm{g}^{-1}$ for HAP to 69,76 and $68 \mathrm{~m}^{2} \mathrm{~g}^{-1}$, and from $101 \mu$ moles $\mathrm{g}^{-1}$ for HAP to 110,170 and $126 \mu$ moles $\mathrm{g}^{-1}$ for TWEEN, PEG and PVA, respectively. These findings demonstrate that HAP i.e. without the addition of precious metals to either the surface or framework, is an active $\mathrm{CO}$ catalyst and that the straightforward inclusion of surfactant during preparation can optimise the catalytic performance.
\end{abstract}

Keywords: CO oxidation, hydroxyapatite, surfactant, acid strength

\section{Introduction}

Hydroxyapatite (HAP), $\mathrm{Ca}_{5}\left(\mathrm{PO}_{4}\right)_{3}(\mathrm{OH})$, is a naturally occurring mineral form of calcium phosphate with interesting properties such as flexible structure, ion-exchange capacity, and the presence of both acidic and basic surface sites. It has, therefore, been of considerable interest in areas such as biomaterials [1], adsorbents [2] and catalysis [3]. HAP has been used as a precious/transition metal catalyst support in a variety of reactions including: oxidation of alcohols [4], methane [5] and CO [6]; selective reduction of $\mathrm{NO}_{\mathrm{x}}$ over copper [7] and silver [8] impregnated HAP; Claisen-Schmidt condensation [9]; Michael addition [10]; Heck [11]; Knoevenagel condensation [12]; and the Diels-Alder reaction [13].

HAP can be synthesised using a dry process e.g. solid-state reaction $[14,15]$, or wet processes e.g. hydrothermal [16], precipitation [17], sol-gel [18], microemulsion [19] or reverse microemulsion [20]. However, the synthesis of high surface area HAP has been a challenge. The main problem is the agglomeration of particles, which in turn leads to HAP with irregular shapes and BET surface area 
predominantly in the range $20-60 \mathrm{~m}^{2} \mathrm{~g}^{-1}$. It has been shown that BET surface areas may be increased by optimising the wet process parameters [21]. The microemulsion technique was used to produce HAP with regular shape [22]; this method employs a water/oil system mixed with at least two surfactants (Span 20 and TWEEN 80), which have a strong influence on the morphology and surface area of HAP.

To the best of our knowledge, there are no reports in the literature that correlate the morphology of HAP to its chemical properties and catalytic activity. HAP based materials have been used as supports for catalysts/metals in $\mathrm{CO}$ oxidation reactions. These reports usually add precious metals e.g. $\mathrm{Au}, \mathrm{Pt}, \mathrm{Pd}$ to HAP; the resulting investigation and discussion of the catalytic activity tend to focus on the precious metals rather than the underlying HAP support. Our study shows that HAP is active in CO oxidation without the addition of precious metal, either substituted into the HAP framework or dispersed as nanoparticles on the surface. Furthermore, we demonstrate that this catalytic activity can be optimised by altering the HAP surface acidity using straightforward surfactant addition during preparation.

\section{Experimental}

\subsection{Materials}

The starting materials for catalyst preparation were; calcium nitrate tetrahydrate ( $>99 \%)$ and ammonium hydrogen phosphate (ACS, >98\%), Alfa Aesar; poly vinyl alcohol (MW 85,000-124,000, 99\% hydrolysed), hexadecyltrimethylammonium-bromide (CTAB) (>99\%), and TWEEN ${ }^{\circledR}$ 60, Sigma Aldrich; poly-ethylene-glycol 400 and polyacrylamide, Fluka and hexadecylamine (synthesis grade), Merck. Materials were used as received without further purification.

\subsection{Catalyst preparation}

HAP was synthesised by dissolving $23.6 \mathrm{~g}$ of $\mathrm{Ca}\left(\mathrm{NO}_{3}\right)_{2} .4 \mathrm{H}_{2} \mathrm{O}$ in $100 \mathrm{~cm}^{3}$ distilled water in a beaker to make a $1 \mathrm{M}$ solution. In another beaker, $7.92 \mathrm{~g}$ of $\left(\mathrm{NH}_{4}\right)_{2} \cdot \mathrm{HPO}_{4}$ was dissolved in $100 \mathrm{~cm}^{3}$ distilled water to make a $0.6 \mathrm{M}$ solution. These quantities give a $\mathrm{Ca} / \mathrm{P}$ molar ratio of 1.67 , which corresponds to the stoichiometry of HAP. The $\mathrm{Ca}\left(\mathrm{NO}_{3}\right)_{2} \cdot 4 \mathrm{H}_{2} \mathrm{O}$ solution was added dropwise to the stirred $\left(\mathrm{NH}_{4}\right)_{2} \cdot \mathrm{HPO}_{4}$ solution, during which pH 10 was maintained by the addition of $30 \mathrm{wt} \% \mathrm{NH}_{4} \mathrm{OH}$. A white precipitate was formed, stirred for $24 \mathrm{~h}$ at room temperature, extracted by filtration, washed and dried at room temperature for $24 \mathrm{~h}$, followed by calcination in air at $550{ }^{\circ} \mathrm{C}$ for $4 \mathrm{~h}$ at $5{ }^{\circ} \mathrm{C} \mathrm{min}^{-1}$ ramp rate. For HAP synthesised using surfactants, $\left(\mathrm{NH}_{4}\right)_{2} \cdot \mathrm{HPO}_{4}$ solution (same quantity and concentration as above) was added dropwise to a $2 \mathrm{wt} \%$ solution of surfactant prepared by dissolving the appropriate amount of surfactant reagent in $50 \mathrm{~cm}^{3}$ water followed by stirring for $1 \mathrm{~h}$. The remainder of the procedure was identical to that for synthesis prepared in the absence of surfactant. Table 1 summarises the samples prepared. 


\subsection{Characterisation}

X-ray diffraction (XRD) was conducted in powder spinning mode at ambient conditions using a Panalytical X'Pert Powder diffractometer with $\mathrm{Cu} \mathrm{K} \alpha$ radiation $(\lambda=1.5406 \AA)$. All powder diffraction patterns were recorded over an angular range of 20 to $70^{\circ}$ with a step size 0.052 and step time $200 \mathrm{~s}$, using an X-ray tube operated at $40 \mathrm{kV}$ and $30 \mathrm{~mA}$ with fixed $0.5^{\circ}$ anti-scatter slit. Mean crystallite particle size was determined from the Scherrer equation using the (002), (211), (310), (222) and (213) crystal planes. Scanning electron microscopy (SEM) images were recorded using a ZEISS Supra 40VP microscope. Prior to imaging, the samples were sputter coated with a thin layer of gold. SEM images were taken using an acceleration voltage of $2 \mathrm{kV}$ and a working distance of approximately $6 \mathrm{~mm}$. Semiquantitative chemical analysis was performed by energy-dispersive X-ray spectroscopy (EDAX) on an Apollo 40 SDD instrument using an acceleration voltage of $20 \mathrm{kV}$ and a working distance of approximately $15 \mathrm{~mm}$. Three areas of each sample were used. Nitrogen adsorption/desorption measurements were carried out using a Micromeritics ASAP 2020 Surface Analyser at $-196{ }^{\circ} \mathrm{C}$. Samples were degassed under vacuum ( $\mathrm{p}<10^{-5} \mathrm{mbar}$ ) for $3 \mathrm{~h}$ at $300^{\circ} \mathrm{C}$ prior to analysis. BET surface areas were calculated in the relative pressure range $0.05-0.30$. The $\mathrm{NH}_{3}$-TPD experiments were performed using a Quantachrome ChemBET Pulsar TPR/TPD instrument. For each measurement, approximately $50 \mathrm{mg}$ of fresh sample was used and initially pretreated in $50 \mathrm{~cm}^{3} \mathrm{~min}^{-1} \mathrm{Ar}$ flow for $1 \mathrm{~h}$ at $200{ }^{\circ} \mathrm{C}$. The catalyst was then cooled down to $30{ }^{\circ} \mathrm{C}$ where $5 \% \mathrm{NH}_{3} / \mathrm{Ar}$ with the same flow rate was introduced for $2 \mathrm{~h}$. Following $\mathrm{NH}_{3}$ adsorption, the catalyst was purged by Ar flow for $60 \mathrm{~min}$ to remove any gas phase and weakly bound $\mathrm{NH}_{3}$. Finally, the temperature was increased at a rate of $5^{\circ} \mathrm{C} \mathrm{min}^{-1}$ up to $600{ }^{\circ} \mathrm{C}$ under $\mathrm{Ar}$ flow at the total rate of $50 \mathrm{~cm}^{3} \mathrm{~min}^{-1}$. The desorption of $\mathrm{NH}_{3}$ was monitored by TCD detector. Particle size analysis was performed on a Zetasizer Nano particle size analyser using dynamic light scattering (DLS). Samples were prepared and analysed according to the method explained in literature for dispersion of nanoparticles in aqueous media [23].

Table 1. List of surfactants used for HAP synthesis

\begin{tabular}{|l|l|l|l|}
\hline $\begin{array}{l}\text { Sample } \\
\text { number }\end{array}$ & Surfactant & Surfactant description & Surfactant type \\
\hline $\mathbf{1}$ & No surfactant & --- & --- \\
\hline $\mathbf{2}$ & PEG & Polyethylene glycol & Non-ionic \\
\hline $\mathbf{3}$ & P213 & $\begin{array}{l}\text { Poly(ethylene glycol)-block-poly(propylene } \\
\text { glycol)-block-poly(ethylene glycol) }\end{array}$ & Non-ionic \\
\hline $\mathbf{4}$ & PVA & Polyvinyl alcohol & Non-ionic \\
\hline $\mathbf{5}$ & TWEEN 80 & Polyoxyethylene Sorbitan Monolaurate & Non-ionic \\
\hline $\mathbf{6}$ & CTAB & Hexadecyl-trimethyl-ammonium bromide & Cationic \\
\hline $\mathbf{7}$ & HDA & Hexadecylamine & Cationic \\
\hline $\mathbf{8}$ & PAM & Polyacrylamide & Cationic \\
\hline
\end{tabular}

\subsection{Catalytic tests}

Catalytic activity was determined by oxidation of CO. Figure 1 illustrates the PFD of the experimental rig. Powder samples were pelletised in a die using a 5 ton hand press, crushed and sieved to particle size 
$<100 \mu \mathrm{m} .0 .5 \mathrm{~g}$ of catalyst was placed in a quartz fixed-bed reactor $(10 \mathrm{~mm}$ internal diameter, $400 \mathrm{~mm}$ length) and secured in the centre of the tube using quartz wool. A temperature-controlled furnace (Carbolite type 3216, Tempatron, PID500/110/330) was used to heat the reactor to the desired temperature. A feed mixture comprising $\mathrm{CO}: \mathrm{O}_{2}: \mathrm{He}$ equal to $1: 2: 2$ and total flow rate of $50 \mathrm{~cm}^{3} \mathrm{~min}^{-1}$ was used in all catalytic tests, giving a GHSV $=1900 \mathrm{~h}^{-1}$. The flow of each gas was maintained using Bronkhorst UK model F-201CV mass flow controllers. The reaction products were monitored by a Hewlett Packard 5890 series II gas chromatograph equipped with a GS-GASPRO column (60 m x 0.32 $\mathrm{mm}$ ) connected via a 6-way gas sampling valve to a thermal conductivity detector. Measurements were recorded at $10{ }^{\circ} \mathrm{C}$ intervals (after holding at that temperature for 5 mins) between 200 and $460{ }^{\circ} \mathrm{C}$ using a heating rate of $10{ }^{\circ} \mathrm{C} \mathrm{min}^{-1}$. Samples were purged with $20 \mathrm{~cm}^{3} \mathrm{~min}^{-1} \mathrm{He}$ for $1 \mathrm{~h}$ at $250{ }^{\circ} \mathrm{C}$ prior to reaction to remove any adsorbed $\mathrm{HC}, \mathrm{CO}$ or moisture.

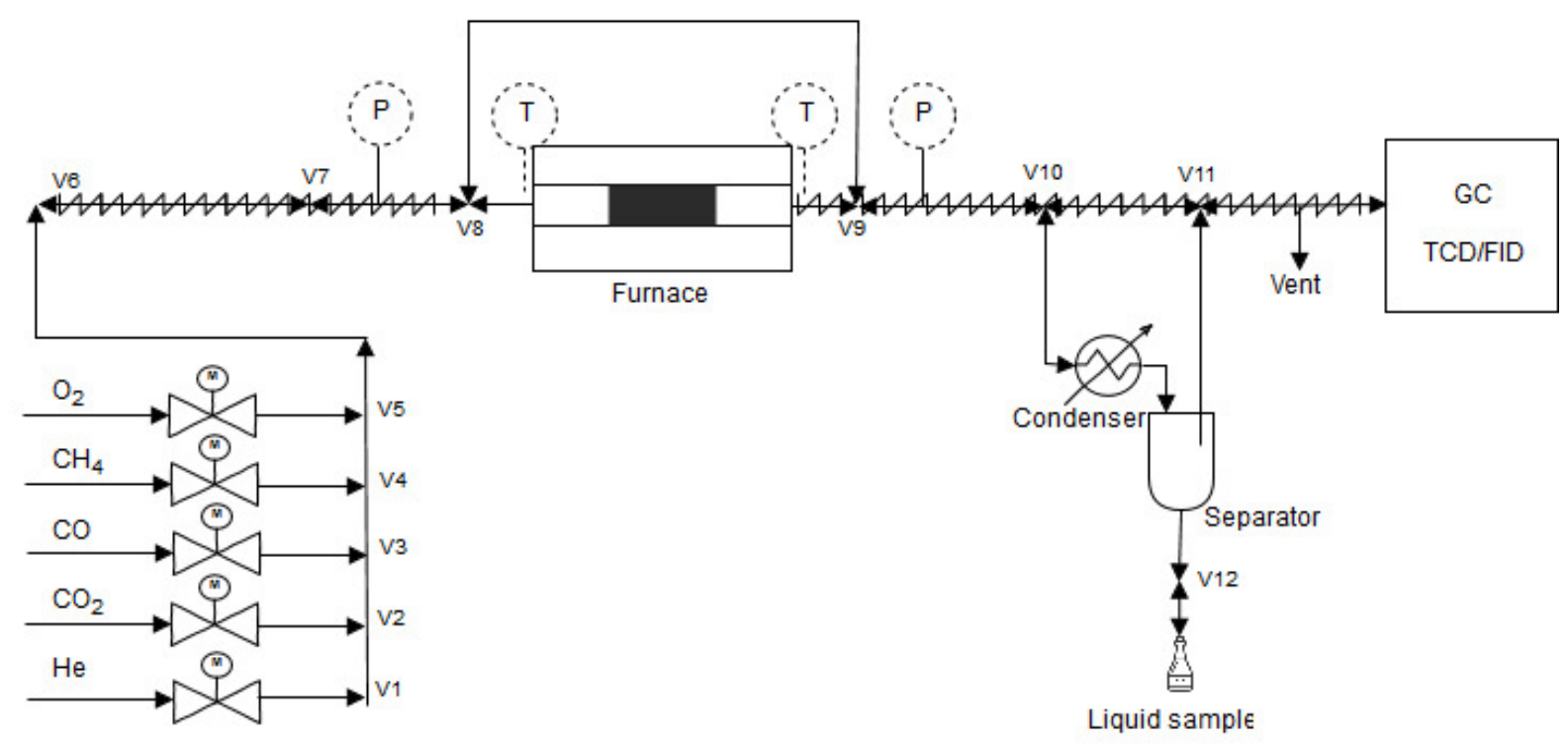

Figure 1. PFD of catalyst testing rig.

\section{Results and Discussion}

\subsection{Characterisation}

The XRD patterns, Figure 2, show that all samples exhibit the characteristic diffraction patterns consistent with the JCPDS diffraction pattern number 01-072-1243 of HAP; the XRD results also match with the NIST data for HAP prepared by Markovic et al. [24]. The diffraction lines $(2 \theta), d$-values $\left(\mathrm{d}_{2 \theta}\right.$ calculated from $2 \theta$ values using the Bragg equation), relative intensities ( $\left.\mathrm{I}_{\text {relative }}\right)$, and hkl indices are listed in Table 2. Interestingly, in most cases the addition of surfactant led to a reduction in mean crystallite size, particularly so in the case of the sample prepared using P123, which was $16 \mathrm{~nm}$. Although surfactants can significantly affect the size of HAP crystals, it is possible to optimise the crystallite size by altering the synthesis method. For instance, Bouyer et. al [25] investigated the effects 
of temperature, $\mathrm{pH}$ and reactant addition rate on the morphology, surface area, purity and mean crystallite dimension of HAP. Their results suggest that, in order to obtain HAP with high purity and monocrystalline structure, reactants should be added at a 'moderate' rate, at temperature lower than 60 ${ }^{\circ} \mathrm{C}$ with a final $\mathrm{pH}$ above 10 . They obtained HAP with crystal size of $24 \mathrm{~nm}$ under optimum conditions $\left(\mathrm{T}=40^{\circ} \mathrm{C}\right.$, acid addition rate $\left.=30 \mathrm{~cm}^{3} \mathrm{~min}^{-1}, \mathrm{pH}>10\right)$.

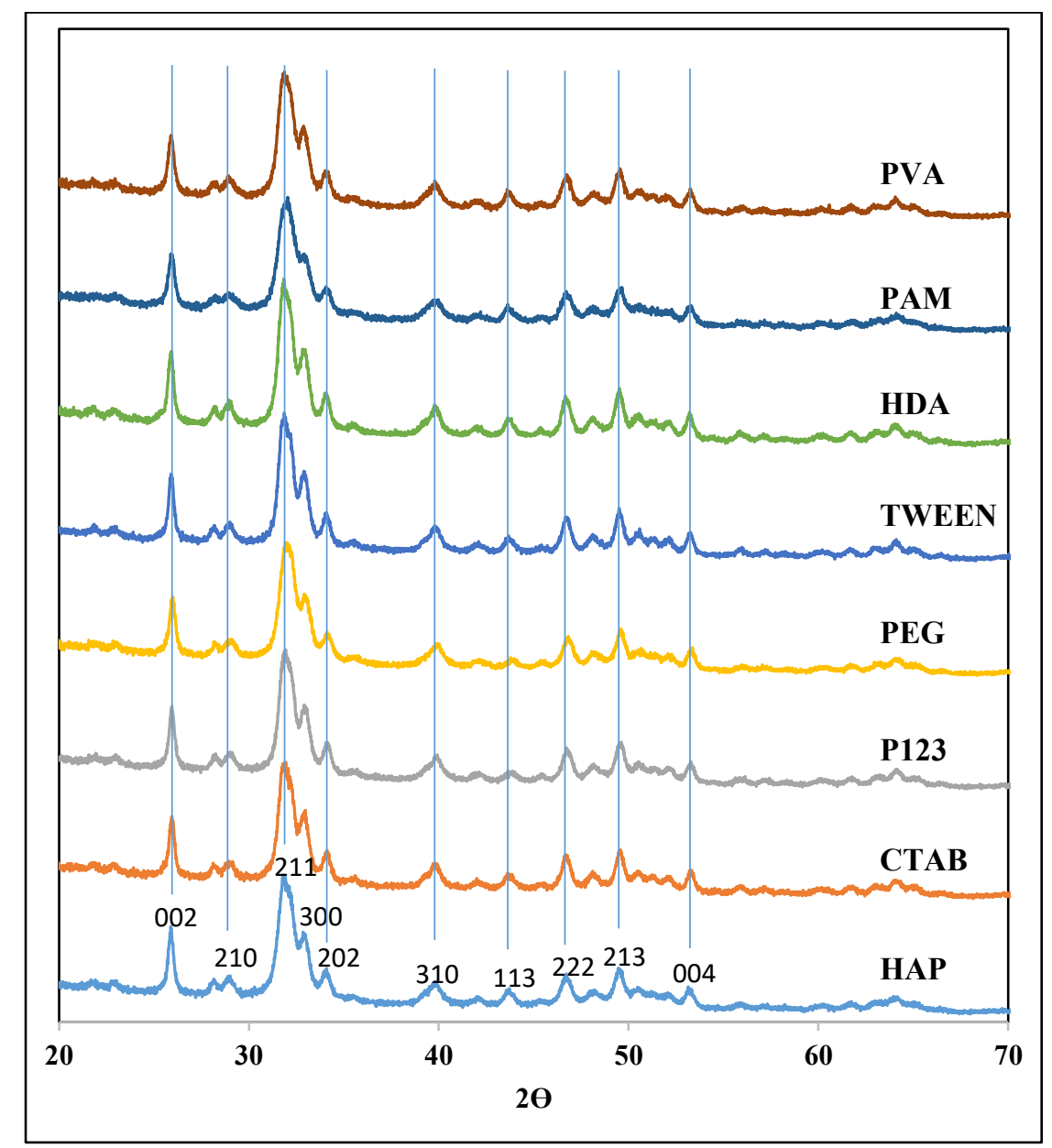

Figure 2. XRD patterns of HAP samples.

The semi-quantitative EDAX results of the different HAP samples prepared in this study, Table 3, confirm that the addition of surfactant increases the $\mathrm{Ca} / \mathrm{P}$ ratio in most of the samples, from 1.66 to as high as 2.1 for PAM, while the only ratio to decrease was CTAB to 1.60. It is not possible to state with confidence whether the ratio for the PEG sample has increased slightly or remained constant, as the difference may be due to experimental error, but this does not affect the general trend towards an increased $\mathrm{Ca} / \mathrm{P}$ ratio following the addition of surfactant. The $\mathrm{Ca} / \mathrm{P}$ ratio plays an important role in determining chemical properties such as acid/base reactivity and ion exchange ability/capacity of the final product. In other words, it is possible to tune the properties of HAP with respect to its application by the straightforward addition of a suitable surfactant during preparation. It should be noted that the mechanical strength of HAP is related to the $\mathrm{Ca} / \mathrm{P}$ ratio, reaching a maximum value at stoichiometric ratio 1.67; the mechanical strength decreases as the ratio diverges from 1.67 , whereby the loss in 
mechanical strength increases with the $\mathrm{Ca} / \mathrm{P}$ ratio difference from 1.67 [26]. Uota et al. observed similar results in their study to prepare high surface area HAP [27]. They obtained HAP with $\mathrm{Ca} / \mathrm{P}$ ratio of 2.2 using TWEEN and nonaoxyethylene dodecyl ether as surfactant. It is well known that the crystal growth of nanomaterials can be controlled by surfactant structure e.g. monomeric, micellar, vesicular, wormlike, and microemulsion, to achieve a desired structure and morphology. Surfactants are adsorbed on the crystal planes of particles and modify the interfacial energy, leading to changes in the rate and direction of crystal growth [28, 29].

Table 2. XRD data for HAP samples; $d_{2 \theta}$ : corresponding d-value, hkl: Miller indices, $I_{\text {relative: }}$ relative intensity.

\begin{tabular}{|c|c|c|c|c|c|c|c|c|c|c|}
\hline \multirow{2}{*}{$2 \theta\left({ }^{\circ}\right)$} & \multirow{2}{*}{$\begin{array}{c}\mathbf{d}_{2 \theta} \\
(\mathbf{n m})\end{array}$} & \multirow{2}{*}{ hkl } & \multicolumn{8}{|c|}{$I_{\text {relative }}$} \\
\hline & & & HAP & CTAB & P123 & PEG & TWEEN & HDA & PAM & PVA \\
\hline 25.9 & 0.344 & 002 & 64 & 66 & 63 & 66 & 63 & 62 & 66 & 60 \\
\hline 28.9 & 0.308 & 210 & 31 & 34 & 30 & 33 & 31 & 33 & 37 & 34 \\
\hline 31.8 & 0.281 & 211 & 100 & 100 & 100 & 100 & 100 & 100 & 100 & 100 \\
\hline 32.9 & 0.272 & 300 & 59 & 68 & 62 & 65 & 65 & 62 & 65 & 63 \\
\hline 34.0 & 0.263 & 202 & 37 & 41 & 37 & 39 & 37 & 37 & 41 & 37 \\
\hline 39.8 & 0.226 & 310 & 28 & 32 & 28 & 28 & 29 & 30 & 31 & 31 \\
\hline 43.8 & 0.206 & 113 & 23 & 24 & 17 & 19 & 22 & 22 & 28 & 23 \\
\hline 46.7 & 0.194 & 222 & 33 & 38 & 32 & 35 & 34 & 35 & 38 & 34 \\
\hline 49.5 & 0.184 & 213 & 37 & 42 & 38 & 41 & 40 & 40 & 40 & 38 \\
\hline 53.2 & 0.172 & 004 & 24 & 27 & 24 & 27 & 24 & 26 & 26 & 25 \\
\hline \multicolumn{3}{|c|}{$\begin{array}{l}\text { Mean crystallite } \\
\text { particle size }(\mathrm{nm})\end{array}$} & 25 & 25 & 16 & 24 & 23 & 25 & 20 & 21 \\
\hline
\end{tabular}

Table 3. EDAX elemental analysis of HAP samples.

\begin{tabular}{cccccccccc}
\hline Sample & HAP & CTAB & P123 & PEG & TWEEN & HDA & PAM & PVA & Ref [24] \\
\hline Ca (wt\%) & 24.1 & 23.4 & 25.6 & 23.4 & 22.8 & 28.4 & 34.8 & 25.5 & 39.2 \\
P (wt\%) & 14.5 & 14.6 & 13.9 & 13.9 & 13.2 & 15.9 & 16.6 & 14.5 & 18.2 \\
Ca/P molar ratio & 1.66 & 1.60 & 1.84 & 1.67 & 1.73 & 1.78 & 2.10 & 1.76 & 1.66 \\
\hline
\end{tabular}

The BET surface areas and average particle size of samples prepared using different surfactants are shown in Table 4. Overall, the BET surface areas, $52-76 \mathrm{~m}^{2} \mathrm{~g}^{-1}$, are above the typical range reported for such materials, 20-60 $\mathrm{m}^{2} \mathrm{~g}^{-1}$. It is, of course, possible to prepare HAP with higher surface areas, but such reports frequently use relatively complicated procedures. For example, Jarudilokkul et al. prepared HAP with BET surface $227 \mathrm{~m}^{2} \mathrm{~g}^{-1}$, using a water in oil (W/O) emulsion liquid membrane system, which required (a) additional reagents to those used in our preparation, (b) 'vigorous stirring' and (c) 2 cycles of centrifugation to completely remove the organic membrane phase [22]. The BET surface area decreased to $58 \mathrm{~m}^{2} \mathrm{~g}^{-1}$ after thermal treatment similar to the conditions used in the preparation described here. Such thermal treatment is well known to reduce surface area, as reported previously by Kamieniak et al., which showed significant surface area reduction of HAP with increasing calcination temperature 
for a similar preparation method to that reported here [30]. In all cases for the preparations in this paper, the addition of surfactant increases the surface areas, with the highest surface area recorded in the case of PEG. The straightforward addition of a surfactant during HAP synthesis is an improvement on the relatively onerous, conventional variation of experimental conditions such as: temperature, aging time, mixing order, $\mathrm{pH}$, reactant addition rate, reactant concentration and calcination temperature. Uota and co-workers [27, 31-33] compared the use of a single surfactant versus a mixture of surfactants on the properties of HAP, the results of which showed that synthesis using mixed surfactants, nonaoxyethylene dodecyl ether $\left(\mathrm{C}_{12} \mathrm{EO}_{9}\right)$ and polyoxyethylene sorbitan monostearate (TWEEN 60), produced the highest surface area HAP. In a similar study, Saha et al. proved that the surfactant plays an important role in the morphology and structure of HAP [33]. They synthesised HAP nanoparticles with four different surfactants using a reverse micelle method under different process conditions. The BET surface area of HAP was increased by the addition of NP5 (polyo-xyethylene-nonylphenyl-ether) as surfactant, under optimised conditions (aqueous/organic ratio 1:5, $\mathrm{pH} 7$, aging time $12 \mathrm{~h}$ and calcination at $450{ }^{\circ} \mathrm{C}$ ).

Surfactant addition affected the average particle size of synthesised samples, Table 4 . The addition of CTAB, TWEEN and HDA surfactants led to increased particle size, relative to HAP, while the remaining surfactants caused a reduction. HAP particle size is known to affect its chemical and physical properties and, therefore, its effectiveness in any final application [34].

Table 4. BET surface areas and average particle size of HAP samples.

\begin{tabular}{ccccccccc}
\hline Sample & HAP & CTAB & P123 & PEG & TWEEN & HDA & PAM & PVA \\
\hline $\begin{array}{c}\text { Surface area } \\
\left(\mathbf{m}^{\mathbf{2}} \mathbf{g}^{-1}\right)\end{array}$ & 52 & 65 & 68 & 76 & 69 & 67 & 58 & 68 \\
$\begin{array}{c}\text { Average particle size } \\
(\boldsymbol{\mu m})\end{array}$ & 2.22 & 2.82 & 1.80 & 1.85 & 2.92 & 3.20 & 2.13 & 2.01 \\
\hline
\end{tabular}

$\mathrm{N}_{2}$ adsorption-desorption, Figure 3, are typical type IV adsorption isotherms that confirm the presence of mesopores with type $\mathrm{H} 1$ hysteresis. These mesopores are formed by the voids between the particles, evidenced by the capillary condensation occurring at relative pressures 0.9 and above i.e. interparticular capillary condensation. Further proof of this is provided by the minimal adsorption at low pressures, as expected for densely formed crystalline HAP devoid of any significant amount of mesopores or micropores. 


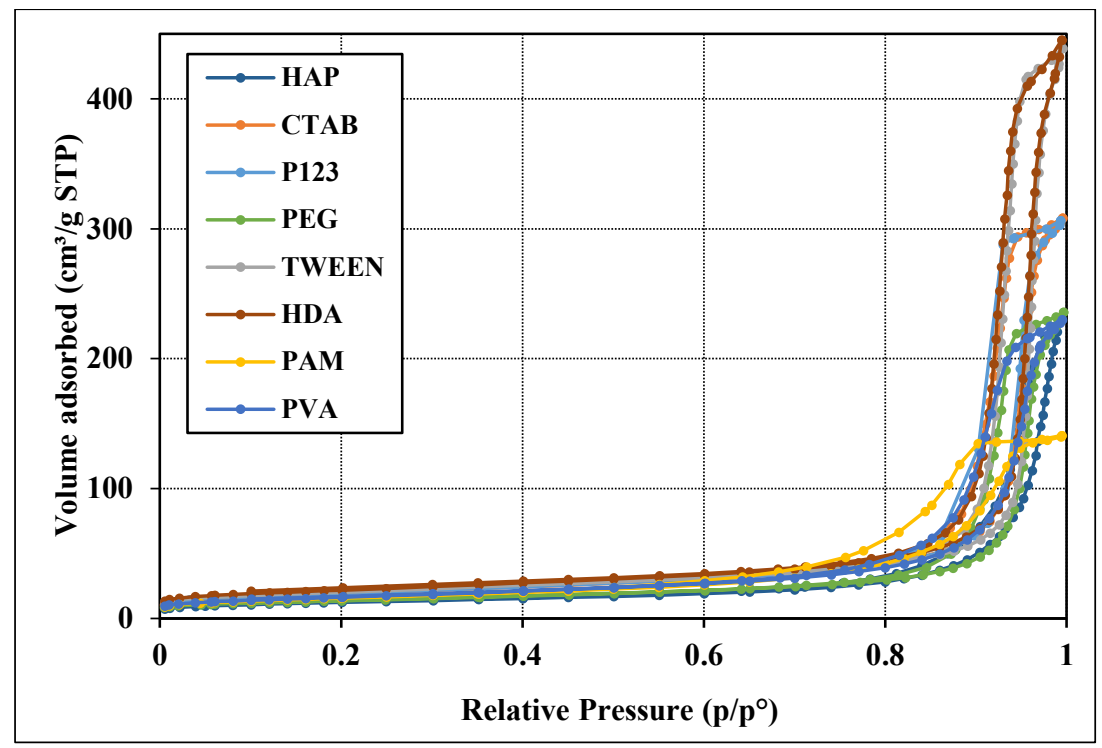

Figure 3. $\mathrm{N}_{2}$ adsorption-desorption isotherms for HAP

SEM images of HAP samples synthesised with different templates are shown in Figure 4. Agglomerated particles are clearly visible on HAP prepared without surfactant, while surfactant-based samples have a more uniform structure.
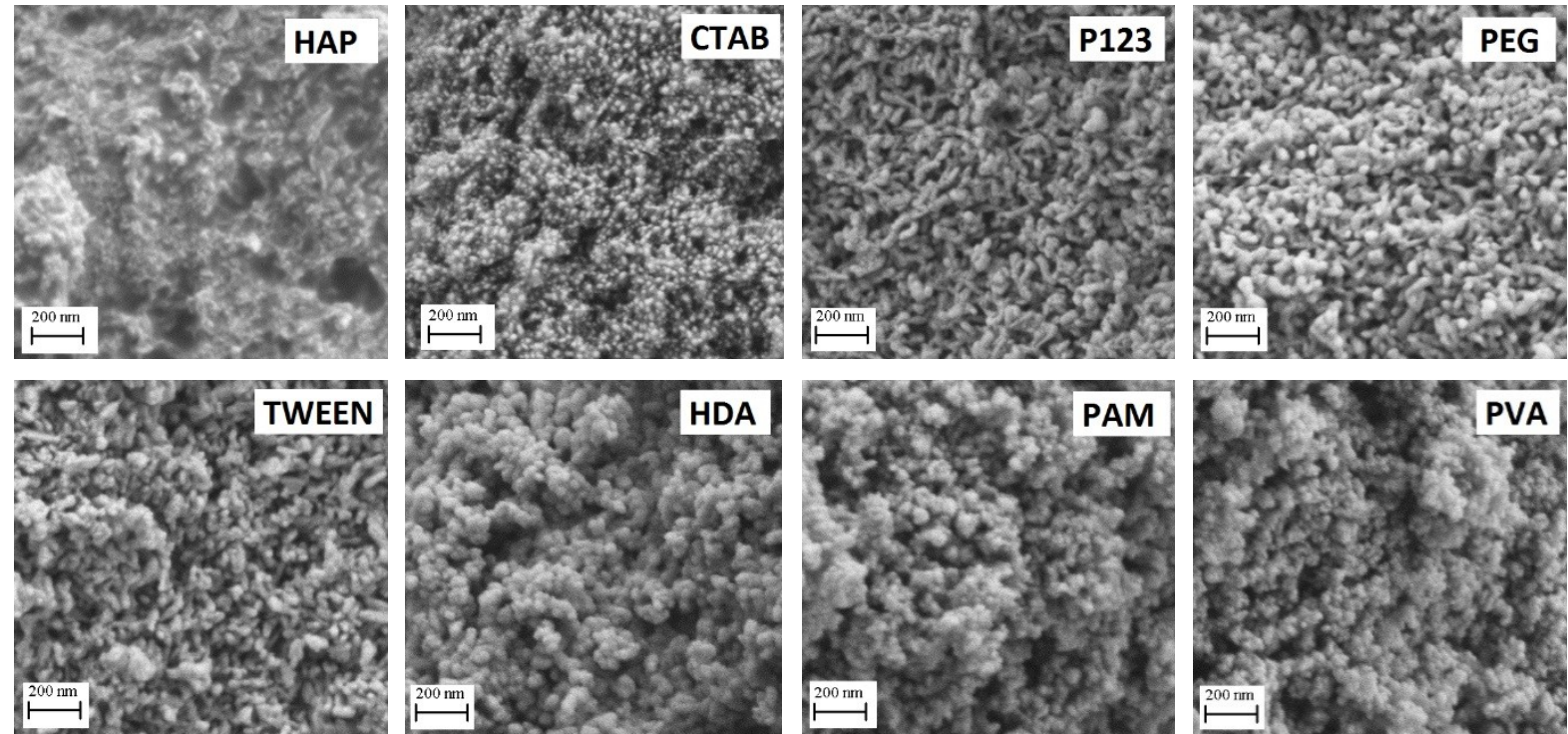

Figure 4. SEM images of hydroxyapatite samples synthesised with different surfactants

In order to understand the effect(s) of surfactant on the morphology and, therefore, other chemical and physical properties of HAP, the nucleation mechanism and growth of hydroxyapatite crystals is evaluated. It is known that when a surfactant is dissolved in water, cationic and non-ionic surfactant molecules form structures that minimise their surface tension. By increasing surfactant concentration to (and beyond) critical micelle concentration (CMC), 'nano-reactors' of surfactant assemblies are present inside the aqueous medium. Depending on the head group size of surfactant, ionic strength and 
hydrophobic tail, the resulting assemblies, Figure 5, are known to have different shapes e.g. rod, spherical, worm-like or lamellar [35]. Phosphate precursors are then added to this surfactant solution, which adsorb onto the surfactant assembly surface due to electrostatic attractions between oppositely charged ions. Thereafter, the addition of calcium precursors results in calcium reaching the surface of surfactant assemblies containing phosphate to form layers of calcium phosphate, which is converted to HAP under the chosen synthesis conditions [35]. The surfactant in effect concentrates the phosphate and calcium precursors such that HAP formation occurs on this surface (although not exclusively). The morphology and surface properties of HAP prepared in the presence of surfactant are, therefore, influenced directly by the properties of the surfactant. Finally, the surfactant is removed by thermal decomposition in air (calcination).

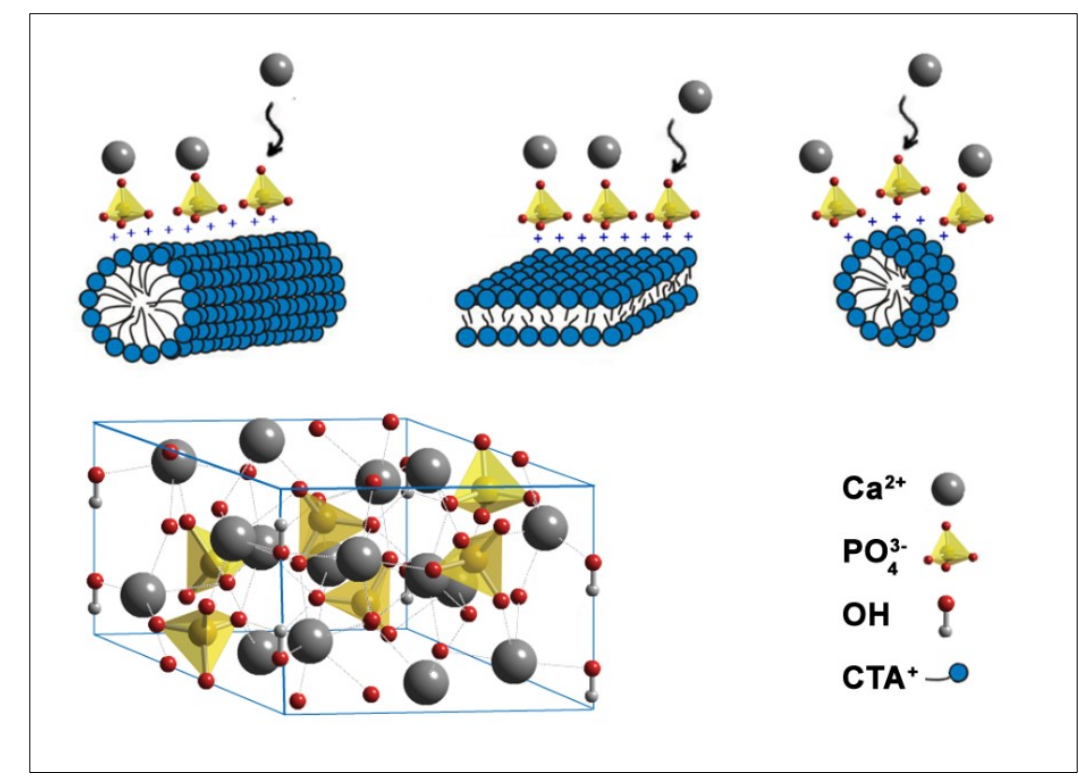

Figure 5. Nucleation and growth of hydroxyapatite crystals over cylindrical, bi-layers and spherical surfactant micelle.

\subsection{CO oxidation}

The catalytic activity of the HAP samples was tested in the oxidation of CO, Figure 6. Preparations using PEG, PVA and TWEEN caused a decrease in CO oxidation temperature; the temperature for $50 \%$ conversion, $\mathrm{T}_{50}$, decreased from $340{ }^{\circ} \mathrm{C}$ for HAP prepared without surfactant to $320^{\circ} \mathrm{C}$ for TWEEN and to $315^{\circ} \mathrm{C}$ for both PEG and PVA. It is interesting to note that this trend towards lower temperature catalytic activity correlates with surface area increases from $52 \mathrm{~m}^{2} \mathrm{~g}^{-1}$ for HAP to 76,68 and $69 \mathrm{~m}^{2} \mathrm{~g}^{-1}$ for PEG, PVA and TWEEN, respectively. 


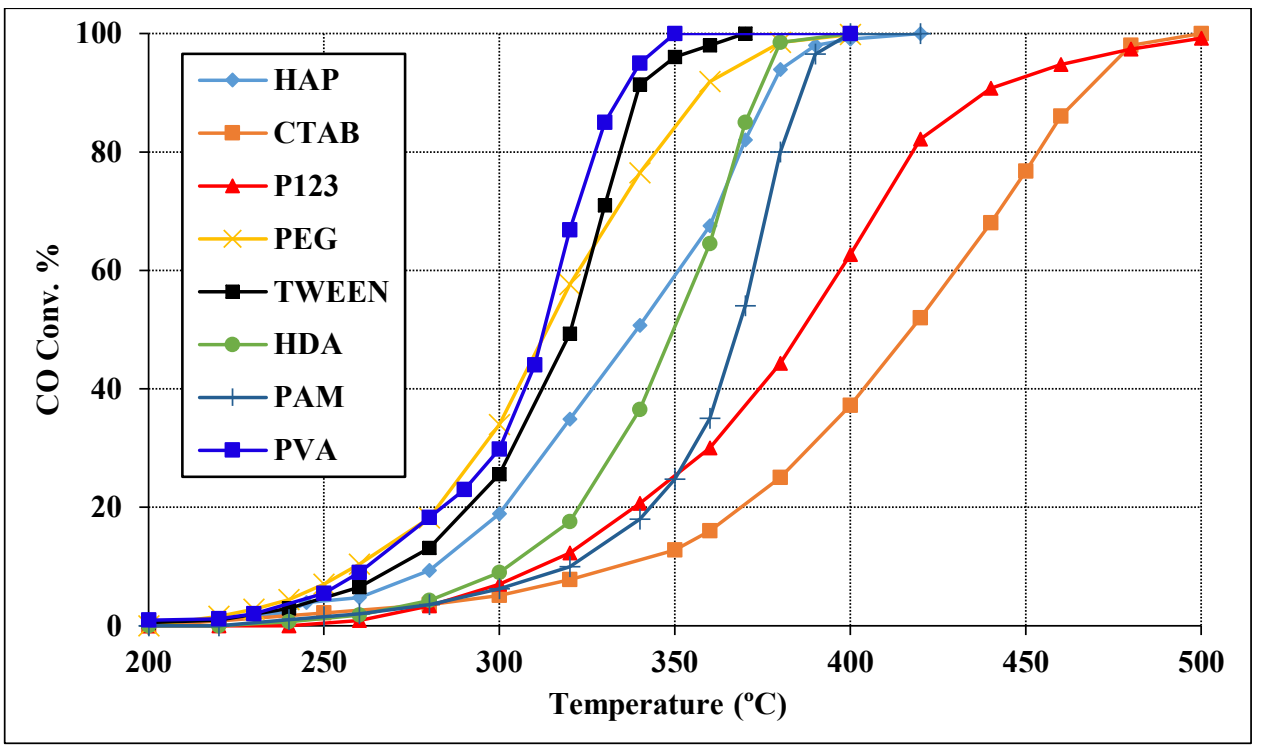

Figure 6. CO oxidation over different HAP samples.

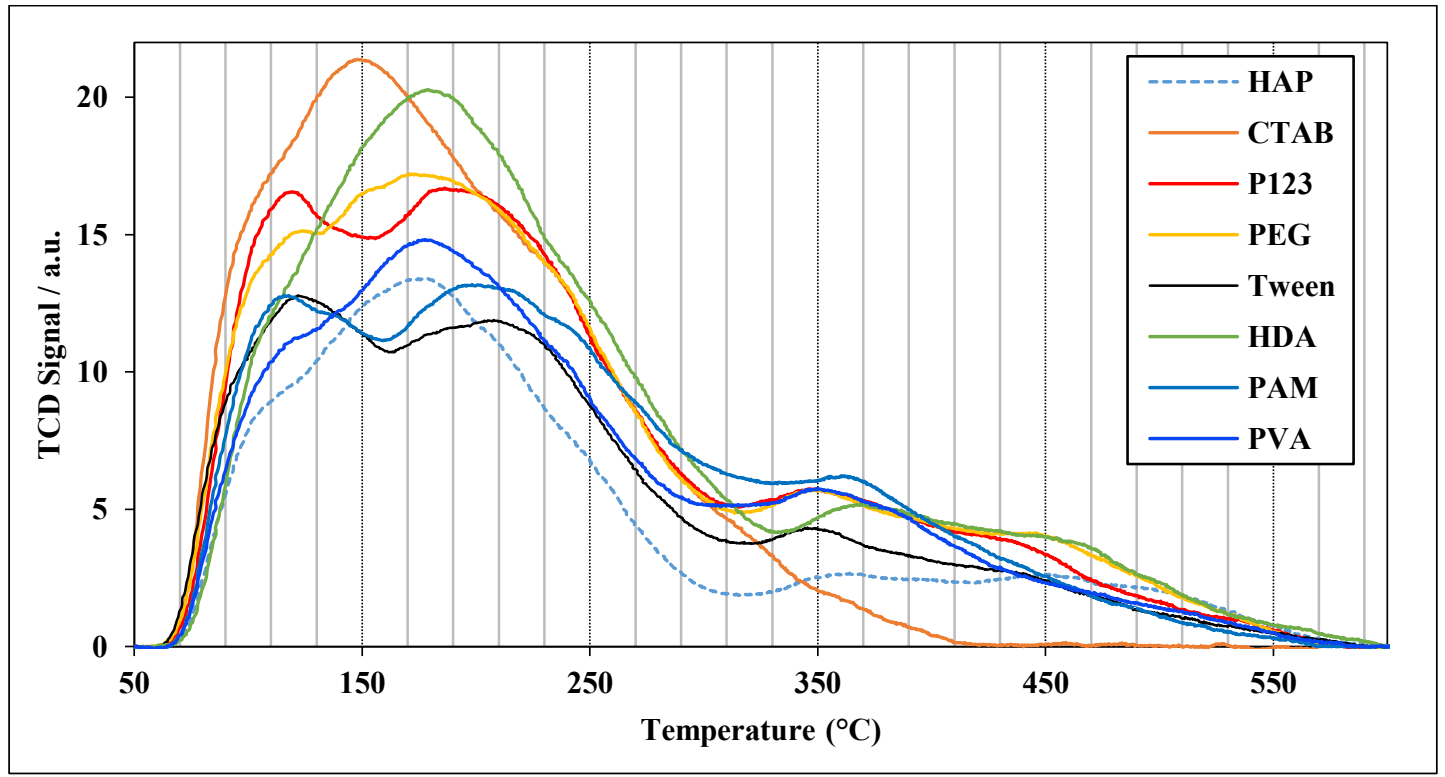

Figure 7. $\mathrm{NH}_{3}-\mathrm{TPD}$ analysis of different $\mathrm{HAP}$ samples.

In the absence of metal nanoparticles, as is the case for the catalysts presented here, the acid sites on the HAP surface are considered to contribute to the $\mathrm{CO}$ oxidation adsorption and reaction. While a full understanding of the $\mathrm{CO}$ oxidation mechanism over acid sites on solid catalysts is still not entirely clear, the fact that $\mathrm{CO}$ has been used specifically as a probe molecule for acid site identification and quantification proves that $\mathrm{CO}$ adsorbs on acid sites [36]. Moreover, the $\mathrm{CO}$ oxidation reaction was shown to require the adsorption of $\mathrm{CO}$ on acid sites, and $\mathrm{O}_{2}$ on basic sites, where the optimum catalytic activity occurred using equal densities of each surface site type [37, 38].

Both acidic and basic sites in HAP originate from $\mathrm{POH}^{-} \mathrm{OH}$ groups. FTIR analysis of HAP, using $\mathrm{CO}$ as a probe molecule, showed that the acidic PO-H groups on the HAP surface produce Brønsted acid sites. These acid sites are due to the phosphate rich terminations of the related powdered sample in which 
these phosphate groups are protonated either once $\left(\mathrm{HPO}_{4}^{2-}\right)$ or twice $\left(\mathrm{H}_{2} \mathrm{PO}_{4}^{-}\right)$[39]. FTIR analysis of HAP using acetylene as probe molecule confirmed that the Brønsted basicity involved in catalytic reactivity was associated with bulk hydroxyl groups available on the channel surface. These basic $\mathrm{OH}^{-}$groups are involved in two nondissociative adsorption modes of acetylene while there is no adsorption by $\mathrm{PO}_{4}^{3--}$; thus, the $\mathrm{OH}^{-}$groups are considered to be the most likely basic active sites involved in catalytic reactions of Hap [40].

The acid sites were studied using $\mathrm{NH}_{3}-\mathrm{TPD}$, Figure 7, to investigate the acid site strength and number, and explore the relation between acid site surface chemistry and $\mathrm{CO}$ oxidation activity. It has been shown that the accessibilities of $\mathrm{Ca}^{2+}$ (strong Lewis sites), and $\mathrm{PO}-\mathrm{H}$ (weak/medium sites) are strongly dependent on the synthesis and drying parameters [41]. Therefore, the quantification of weak/medium and strong acid sites can provide useful insight into how surfactant addition can alter the acid sites distribution, such that the properties of HAP as heterogeneous catalyst can be tailored according to the requirement for Brønsted or Lewis acid sites.

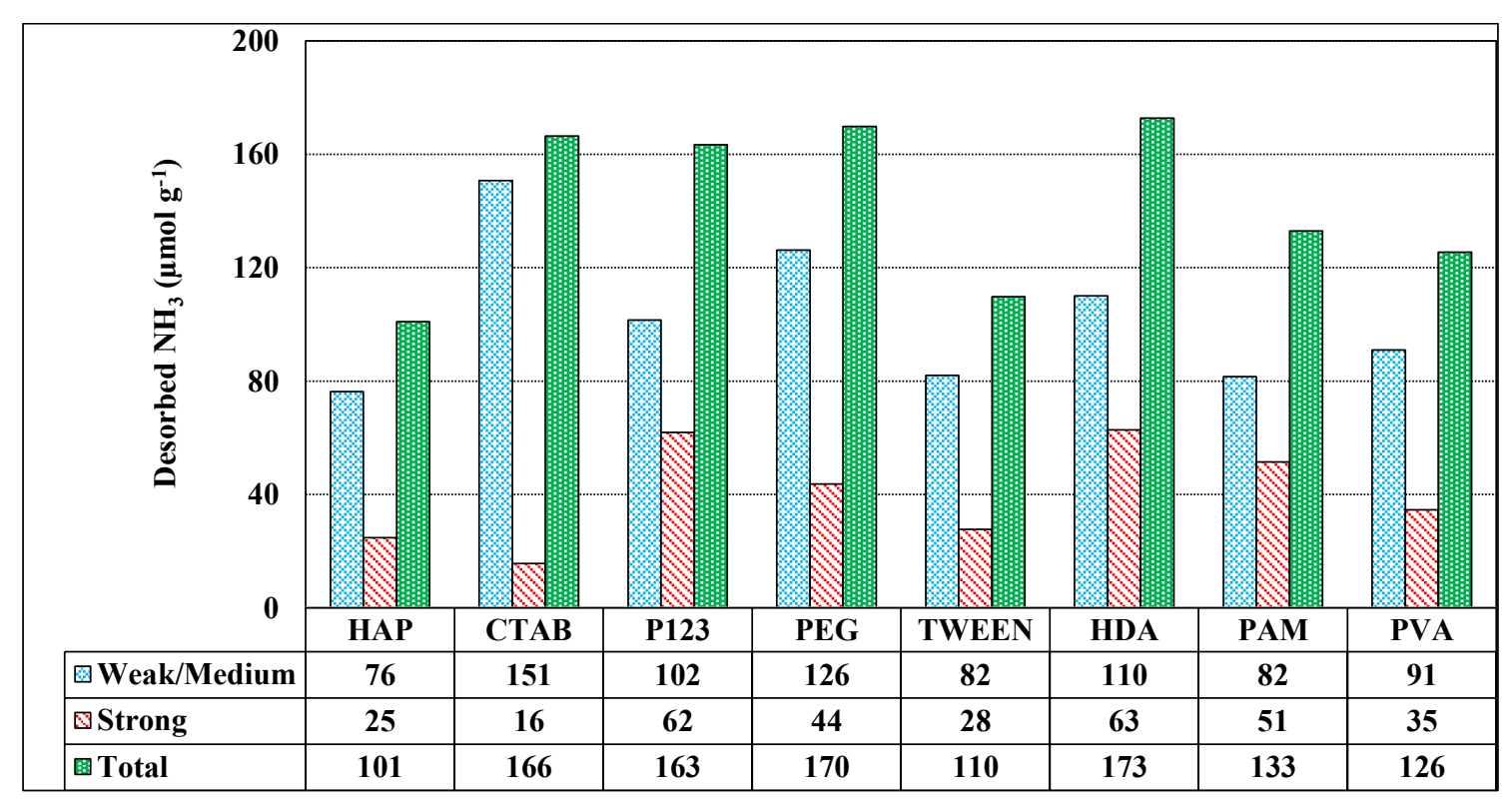

Figure 8. Quantitative analysis of acid sites over different HAP samples using $\mathrm{NH}_{3}$-TPD. 'Weak/Medium' and 'Strong' sites are assigned from desorption in the ranges $100-250{ }^{\circ} \mathrm{C}$ and $>300{ }^{\circ} \mathrm{C}$, respectively.

Figure 8 shows the acid site molar densities of the catalysts, where 'weak/medium' sites are in the range $100-250{ }^{\circ} \mathrm{C}$, and 'strong' sites are $>300{ }^{\circ} \mathrm{C}$. Overall, the addition of surfactant has a significant effect on the total number and distribution of acid sites. All samples prepared with surfactant have higher quantities of total acid sites than HAP; these higher quantities correlate well with the higher surface areas recorded for the surfactant based syntheses. The $\mathrm{NH}_{3}$-TPD results are in good agreement with the $\mathrm{Ca} / \mathrm{P}$ ratios from Table 3. For example, the lowest $\mathrm{Ca} / \mathrm{P}$ ratio recorded for the $\mathrm{CTAB}$ sample, 1.60, contains the lowest quantity of strong acid sites, $16 \mu \mathrm{mol} \mathrm{g}{ }^{-1}$, and also has the lowest CO oxidation activity $\left(\mathrm{T}_{50}=415^{\circ} \mathrm{C}\right)$. However, a greater $\mathrm{Ca} / \mathrm{P}$ ratio is not necessarily an indication of high catalytic 
activity. Although the PAM sample has the highest $\mathrm{Ca} / \mathrm{P}$ ratio (2.10), it is not the most active catalyst for $\mathrm{CO}$ conversion. This relatively low activity could be attributed (at least in part) to the low surface area of this sample $\left(58 \mathrm{~m}^{2} \mathrm{~g}^{-1}\right)$, which simply reduces the number of acid sites to catalyse the reaction. Comparing HAP again with the more active catalysts, there is a clear correlation between the decreasing $\mathrm{T}_{50}$ values and increasing quantities of each of the weak/medium, strong and total acid sites. For example, the total quantities of acid sites increased from $101 \mu$ moles $\mathrm{g}^{-1}$ for $\operatorname{HAP}\left(\mathrm{T}_{50}, 340{ }^{\circ} \mathrm{C}\right)$ to 110 $\mu$ moles $\mathrm{g}^{-1}$ for TWEEN $\left(320^{\circ} \mathrm{C}\right), 126 \mu$ moles $\mathrm{g}^{-1}$ for PVA $\left(315^{\circ} \mathrm{C}\right)$ and $170 \mu$ moles $\mathrm{g}^{-1}$ for PEG $(315$ ${ }^{\circ} \mathrm{C}$ ), Figure 9. A similar correlation is found between the light off temperatures measured at $10 \%$ conversion; $\mathrm{T}_{10}$ values decreased from $281{ }^{\circ} \mathrm{C}$ for HAP to $271{ }^{\circ} \mathrm{C}$ for TWEEN, $262{ }^{\circ} \mathrm{C}$ for PVA and 259 ${ }^{\circ} \mathrm{C}$ for PEG. These trends match with the results for increasing surface area, as increased surface area results in a greater number of acid sites on the surface. For the catalysts that were less active than HAP, our analysis of the numerical results showed that there does not appear to be any straightforward trend/correlation between the activities of the catalysts (as a group) and either the surface areas or acid site densities. It seems likely, therefore, that other factors may be responsible for the lower activity.

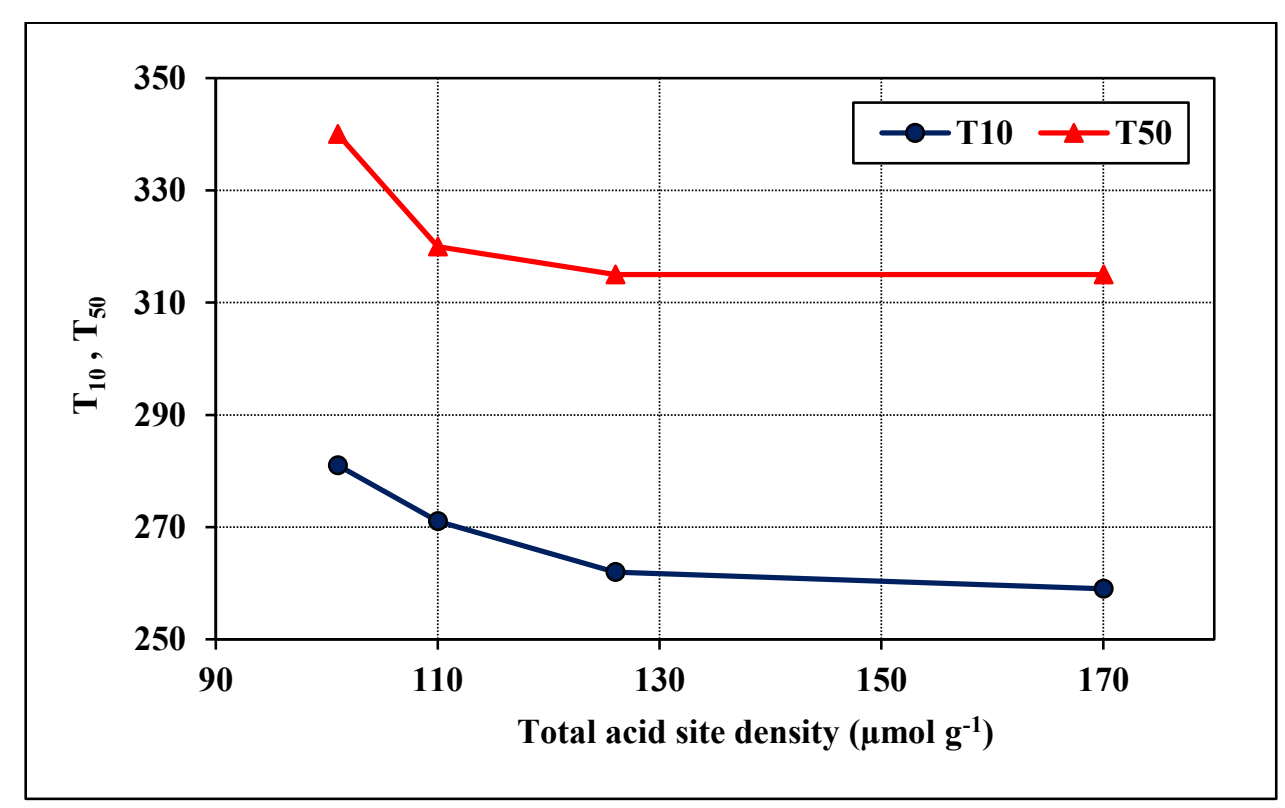

Figure 9. $\mathrm{T}_{10}$ and $\mathrm{T}_{50}$ values as a function of acid site density; samples are (from left to right) HAP, TWEEN, PVA and PEG.

\section{Conclusions}

This study shows the impact of using surfactants on the physical and chemical properties of hydroxyapatite for heterogeneous catalyst applications. Surfactants can change the morphology of the HAP by changing the nucleation and growth of hydroxyapatite crystals to cylindrical, bi-layers and spherical. Moreover, other properties of HAP such as surface area, $\mathrm{Ca} / \mathrm{P}$ ratio, acid sites distribution and 
strength are altered depending on the surfactant type, which consequently affects the catalyst activity of the HAP sample in oxidation reactions.

\section{References}

[1] H. Zhou, J. Lee, Nanoscale hydroxyapatite particles for bone tissue engineering, Acta Biomaterialia, 7 (2011) 2769-2781.

[2] K.L. Lin, J.Y. Pan, Y.W. Chen, R.M. Cheng, X.C. Xu, Study the adsorption of phenol from aqueous solution on hydroxyapatite nanopowders, Journal of Hazardous Materials, 161 (2009) 231-240.

[3] Z. Dinglin, Z. Huawen, Z. Xianying, L. Yimin, C. Hua, L. Xianjun, Application of hydroxyapatite as catalyst and catalyst carrier, Prog Chem, 23 (2011) 687-694.

[4] K. Kaneda, K. Mori, T. Hara, T. Mizugaki, K. Ebitani, Design of hydroxyapatite-bound transition metal catalysts for environmentally-benign organic syntheses, Catalysis Surveys from Asia, 8 (2004) 231-239. [5] J. Kamieniak, P.J. Kelly, C.E. Banks, A.M. Doyle, Methane emission management in a dual-fuel engine exhaust using Pd and Ni hydroxyapatite catalysts, Fuel, 208 (2017) 314-320.

[6] N. Phonthammachai, Z. Ziyi, G. Jun, H.Y. Fan, T.J. Whitea, Synthesis of high performance hydroxyapatite-gold catalysts for CO oxidation, Gold Bulletin, 41 (2008) 42-50.

[7] H. Tounsi, S. Djemal, C. Petitto, G. Delahay, Copper loaded hydroxyapatite catalyst for selective catalytic reduction of nitric oxide with ammonia, Applied Catalysis B: Environmental, 107 (2011) 158163.

[8] P.A. Kumar, M.P. Reddy, L.K. Ju, H.H. Phil, Novel Silver Loaded Hydroxyapatite Catalyst for the Selective Catalytic Reduction of NOx by Propene, Catalysis Letters, 126 (2008) 78.

[9] S.d. Sebti, A. Solhy, R. Tahir, A. Smahi, Modified hydroxyapatite with sodium nitrate: an efficient new solid catalyst for the Claisen-Schmidt condensation, Applied Catalysis A: General, 235 (2002) 273281.

[10] M. Zahouily, Y. Abrouki, B. Bahlaouan, A. Rayadh, S. Sebti, Hydroxyapatite: new efficient catalyst for the Michael addition, Catalysis Communications, 4 (2003) 521-524.

[11] K. Mori, T. Hara, M. Oshiba, T. Mizugaki, K. Ebitani, K. Kaneda, Catalytic investigations of carboncarbon bond-forming reactions by a hydroxyapatite-bound palladium complex, New Journal of Chemistry, 29 (2005) 1174-1181.

[12] M.K. Pillai, S. Singh, S.B. Jonnalagadda, Solvent-Free Knoevenagel Condensation over Cobalt Hydroxyapatite, Synthetic Communications, 40 (2010) 3710-3715.

[13] K. Mori, T. Hara, T. Mizugaki, K. Ebitani, K. Kaneda, Hydroxyapatite-Bound Cationic Ruthenium Complexes as Novel Heterogeneous Lewis Acid Catalysts for Diels-Alder and Aldol Reactions, Journal of the American Chemical Society, 125 (2003) 11460-11461.

[14] R.A. Young, D.W. Holcomb, Variability of hydroxyapatite preparations, Calcified tissue international, 34 Suppl 2 (1982) S17-32.

[15] J.M. Cao, J. Feng, S.G. Deng, X. Chang, J. Wang, J.S. Liu, P. Lu, H.X. Lu, M.B. Zheng, F. Zhang, J. Tao, Microwave-assisted solid-state synthesis of hydroxyapatite nanorods at room temperature, Journal of Materials Science, 40 (2005) 6311-6313.

[16] J.S. Earl, D.J. Wood, S.J. Milne, Hydrothermal synthesis of hydroxyapatite, Journal of Physics: Conference Series, 26 (2006) 268.

[17] S.S.A. Abidi, Q. Murtaza, Synthesis and Characterization of Nano-hydroxyapatite Powder Using Wet Chemical Precipitation Reaction, Journal of Materials Science \& Technology, 30 (2014) 307-310.

[18] D.-M. Liu, T. Troczynski, W.J. Tseng, Water-based sol-gel synthesis of hydroxyapatite: process development, Biomaterials, 22 (2001) 1721-1730.

[19] G.C. Koumoulidis, A.P. Katsoulidis, A.K. Ladavos, P.J. Pomonis, C.C. Trapalis, A.T. Sdoukos, T.C. Vaimakis, Preparation of hydroxyapatite via microemulsion route, Journal of Colloid and Interface Science, 259 (2003) 254-260. 
[20] G. Guo, Y. Sun, Z. Wang, H. Guo, Preparation of hydroxyapatite nanoparticles by reverse microemulsion, Ceramics International, 31 (2005) 869-872.

[21] C. Verwilghen, S. Rio, A. Nzihou, D. Gauthier, G. Flamant, P.J. Sharrock, Preparation of high specific surface area hydroxyapatite for environmental applications, Journal of Materials Science, 42 (2007) 6062-6066.

[22] S. Jarudilokkul, W. Tanthapanichakoon, V. Boonamnuayvittaya, Synthesis of hydroxyapatite nanoparticles using an emulsion liquid membrane system, Colloids and Surfaces A: Physicochemical and Engineering Aspects, 296 (2007) 149-153.

[23] V. Hackley, J. Clogston, Measuring the size of nanoparticles in aqueous media using batch-mode dynamic light scattering, NIST Special Publication, 1200 (2007) 6.

[24] M. Markovic, B.O. Fowler, M.S. Tung, Preparation and Comprehensive Characterization of a Calcium Hydroxyapatite Reference Material, Journal of research of the National Institute of Standards and Technology, 109 (2004) 553-568.

[25] E. Bouyer, F. Gitzhofer, M.I. Boulos, Morphological study of hydroxyapatite nanocrystal suspension, Journal of Materials Science: Materials in Medicine, 11 (2000) 523-531.

[26] R.W. Bucholz, A. Carlton, R. Holmes, Interporous hydroxyapatite as a bone graft substitute in tibial plateau fractures, Clinical orthopaedics and related research, (1989) 53-62.

[27] M. Uota, H. Arakawa, N. Kitamura, T. Yoshimura, J. Tanaka, T. Kijima, Synthesis of High Surface Area Hydroxyapatite Nanoparticles by Mixed Surfactant-Mediated Approach, Langmuir, 21 (2005) 4724-4728.

[28] M.S. Bakshi, How Surfactants Control Crystal Growth of Nanomaterials, Crystal Growth \& Design, 16 (2016) 1104-1133.

[29] A.R. Harikrishnan, P. Dhar, P.K. Agnihotri, S. Gedupudi, S.K. Das, Effects of interplay of nanoparticles, surfactants and base fluid on the surface tension of nanocolloids, The European Physical Journal E, 40 (2017) 53.

[30] J. Kamieniak, P.J. Kelly, C.E. Banks, A.M. Doyle, Mechanical, pH and Thermal Stability of Mesoporous Hydroxyapatite, Journal of Inorganic and Organometallic Polymers and Materials, 28 (2018) 84-91.

[31] M. Uota, H. Arakawa, N. Kitamura, T. Yoshimura, J. Tanaka, T. Kijima, HIGH SURFACE AREA HYDROXYAPATITE NANOPARTICLES SYNTHESIZED VIA CALCIUM STEARATE ENCAPSULATION BY MIXED SURFACTANT-MEDIATED APPROACH, Phosphorus Research Bulletin, 19 (2005) 288-293.

[32] R. Othman, Z. Mustafa, C.W. Loon, A.F.M. Noor, Effect of Calcium Precursors and pH on the Precipitation of Carbonated Hydroxyapatite, Procedia Chemistry, 19 (2016) 539-545.

[33] S.K. Saha, A. Banerjee, S. Banerjee, S. Bose, Synthesis of nanocrystalline hydroxyapatite using surfactant template systems: Role of templates in controlling morphology, Materials Science and Engineering: C, 29 (2009) 2294-2301.

[34] Y.X. Pang, X. Bao, Influence of temperature, ripening time and calcination on the morphology and crystallinity of hydroxyapatite nanoparticles, Journal of the European Ceramic Society, 23 (2003) 16971704.

[35] M. Mujahid, S. Sarfraz, S. Amin, On the Formation of Hydroxyapatite Nano Crystals Prepared Using Cationic Surfactant, Materials Research, 18 (2015) 468-472.

[36] G. Martins, G. Berlier, C. Bisio, S. Coluccia, H. Pastore, L. Marchese, Quantification of Brønsted acid sites in microporous catalysts by a combined FTIR and NH3-TPD study, The Journal of Physical Chemistry C, 112 (2008) 7193-7200.

[37] A. Salker, S. Naik, Mechanistic study of acidic and basic sites for CO oxidation over nano based Co2-xFexWO6 catalysts, Applied Catalysis B: Environmental, 89 (2009) 246-254.

[38] V. Radkevich, A. Ivko, Y.G. Egiazarov, Effect of the Acid-base Properties of the Support on the Activity of Pd-zeolite Catalysts for Co Oxidation, Kinetics and catalysis, 42 (2001) 520-524.

[39] S. Diallo-Garcia, M.B. Osman, J.-M. Krafft, S. Boujday, C. Guylène, Discrimination of infrared fingerprints of bulk and surface $\mathrm{POH}$ and $\mathrm{OH}$ of hydroxyapatites, Catal. Today, 226 (2014) 81-88. 
[40] S. Diallo-Garcia, M.B. Osman, J.-M. Krafft, S. Casale, C. Thomas, J. Kubo, G. Costentin, Identification of Surface Basic Sites and Acid-Base Pairs of Hydroxyapatite, The Journal of Physical Chemistry C, 118 (2014) 12744-12757.

[41] M. Ben Osman, S. Diallo Garcia, J.-M. Krafft, C. Methivier, J. Blanchard, T. Yoshioka, J. Kubo, G. Costentin, Control of calcium accessibility over hydroxyapatite by post-precipitation steps: influence on the catalytic reactivity toward alcohols, Physical Chemistry Chemical Physics, 18 (2016) 2783727847. 